\title{
El viaje rumbo a Estados Unidos de Dennis Sulema Díaz Alvarenga
}

\author{
Por Victor Diaz* y Dennis Diaz**
}

\section{Del 19 de febrero al 29 de marzo de 2011}

A eso de las cuatro de la mañana salimos de Monte Fresco, Morazán, Yoro. Éramos Vilma, Juan Carlos, Alberto y yo. Nos alumbrábamos con luz de ocote y nos cayó un poco de lluvia que en ese momento se convirtió en la bendición del viaje después de caminar en un lodazal. Llegamos al lugar donde nos esperaba el carro para llegar a Morazán, Yoro. Luego seguimos hasta llegar a San Pedro Sula. Tuvimos una cena en donde recibimos la bendición del padre José Santos para que tuviéramos un viaje de éxito en compañía de Dios. Luego nos fuimos a dormir. Ahí nos quedamos esa noche para salir al día siguiente bastante temprano. Ahí estábamos sólo Juan y yo, Dennis Sulema Díaz Alvarenga.

Ahí empezó los más cómodo del viaje, en bus y bien sentados hasta llegar a Puerto Cortés para tomar el bus que nos llevaría a la frontera de Corinto. Ahí los rateros de la aduana nos sacaron dinero porque Juan era menor de 21 años y no teníamos permiso de un abogado para poder salir del país. Ahí fue el primer robo y el otro fue para entrar a Guatemala. Seguimos hasta llegar a Santa Elena, donde nos quedamos la siguiente noche. A la mañana siguiente salimos rumbo a El Naranjo, donde cambiamos las monedas y cruzamos el río en una canoa para llegar a San Andrés. Fue la última noche en que dormimos en cama en un pequeño hotel y hasta comimos carne de venado.

Aquí comienza la verdadera aventura. Salimos en un carro junto con una gran cantidad de personas que veníamos en busca del mal llamado 'sueño americano'. Nos llevaron por un camino donde el carro sirvió de caballo por lo angosto de la senda. Fueron varias horas de maltrato en ese recorrido. Ese jalón costaba 250 pesos

* Promotor social del Equipo de Reflexión, Investigación y Comunicación (ERIC), El Progreso, Honduras.

** Migrante hondureña, hermana de Victor. 
más 100 pesos para el pase de un río en cayuco para llegar al lugar llamado El Pozo, donde está la línea del tren. No nos quedamos porque allí vimos a un grupo de personas que se supone que eran de los famosos Zetas. Entonces nos fuimos para el pueblo siguiente, llamado San Pedro Tabasco, a $1 \mathrm{~km}$ del pozo.

Pasamos la primera noche en el 'hotel El Bosque' con cama terrenal y sábana de la nada. Qué frío tan cruel. Fueron dos noches durmiendo a la intemperie. Luego vino la lluvia y nos tocó dormir en un gallinero de donde a media noche nos sacaron carrera Los Zetas y nos fuimos a dormir a un potrero. Al día siguiente continuamos rumbo a Tenosique. Veníamos en un grupo de unas veinte personas.

Puestos en Tenosique nos separamos del grupo y seguimos sólo Juan y yo. Caminamos por toda la línea hasta que se hizo de noche y nos tocó la primera noche solos. Teníamos mucho miedo. Tuvimos que comer tortillas que habíamos comprado y algo de cuajada, sardina y unos huevos duros que llevábamos desde Honduras pero que todavía estaban buenos. Después de comer seguimos nuestro recorrido. Se hizo tarde y dormimos en un potrero. Traíamos una colcha que estaba buenísima pero me tocó desvelarme porque Juan era una piedra y alguien tenía que vigilar.

Amaneció y seguimos caminando y caminando. Cruzamos un pueblito y seguimos. No sé cuántos kilómetros caminamos y a lo lejos vimos dos hombres descansando, así que ahí hicimos escala y descansamos. Como todavía llevábamos tortilla y cuajada las compartimos los cuatro. Más tarde pasó un grupo más y nosotros nos quedamos para esperar. Pasaron dos noches y el problema fue que nos estábamos quedando sin comida. De repente se le ocurrió a un garrobo dejarse ver y nos fuimos de cacería. Éramos cinco personas ya. Primero el garrobo se nos escapó pero después lo encontramos y no se salvó. Así que comimos garrobo asado. Dormimos una noche más en un corral con una fogata y con una llanta por cama. Amaneció otra vez y ya el grupo se hizo de unas 15 personas más o menos. Recuerdo algunos de sus nombres y sobrenombres: 'el güero', Wendy, Manuel, 'el patojo'. En el grupo sólo habíamos dos mujeres y veníamos bien protegidas gracias a Dios.

Ya por la tarde llegó el momento. Todos estábamos emocionados pues se terminaba la espera. "¡Viene el tren, corran mujeres, tengan cuidado, corran a la par de él pues por aquí pasa despacio! Corran, corran y cuando estén seguras se agarran duro, nosotros las ayudaremos a subir", dijeron los de más experiencia. Yo tenía algo de nervios, supongo que era normal. Pero la gente decía, "vamos, que si no agarramos este tren no sabemos cuánto tiempo más tendremos que esperar". Así que lo hicimos. Qué emoción sentí cuando estábamos arriba de esa gran bestia. Llegamos al siguiente pueblo, Coatzacoalcos, y allí compramos tamalitos de elote y bolsas para meternos en ellas y así evitar mojarnos. Se acercó la noche y la lluvia y nosotros a dormir allá arriba, y esa cosa caminando a gran velocidad.

Se unieron otras tres personas a nuestro grupo que ya era como de 19 personas. Los hombres se armaron de palos y piedras para protegernos pues el tren llevaba mucha gente y de todo un poco. Llegamos a Horizabal. El tren no se había terminado de parar cuando unos 'garroteros' nos empezaron a sacar carreras. Corrimos y dimos una gran vuelta para salir adelante, donde podíamos tomar el tren nuevamente. Comimos algo, bebimos y no podía faltar la fogata, pues el frío es fuertísimo. Había una casa donde regalaban café y fuimos. Los hombres, para entrar 
en calor, se echaban sus tragos de las famosas Caguamas. Al rato se acercaron unos chapines y les ofrecieron Caguamas. Ellos dijeron que no, que ellos sólo cerveza Gallo tomaban. Ese fue el chiste de varios días.

Salió el primer tren y todos estábamos listos pero iba demasiado rápido y fueron pocos los que lograron tomarlo. Fue en ese momento en que a un chapín que intentaba subir, para su desgracia le cortó un pie. Fue algo bastante fuerte. La verdad, yo no tuve el valor de verle pues, aunque me considero una persona fuerte, pensé que no era prudente porque los nervios quizá no estaban tan bien. Y como sé que la sangre no es mi mejor amiga, decidí mantenerme a distancia. Era triste escucharlo cuando le gritaba a su compañero que no lo dejara, que lo esperara, que él no se quería quedar en ese lugar. A los pocos minutos llegó la ambulancia y se lo llevaron al hospital.

Qué horrible cuando estábamos en espera, cualquier carro que pasaba nos ponía a parar la oreja. Estábamos asustados o más bien preocupados. Llegó el momento, venía la bestia. El tren venía despacio, quizá porque les dio lástima lo que le pasó al chapín. Nos subimos con un frío que nos carcomía los huesos, pero ya estábamos arriba. Buscamos cómo ubicarnos bien en la plancha que une a un vagón con el siguiente y sacamos la colcha para amortiguar el frío. Más adelante había por allá unas casas. El tren hizo una parada y las personas estaban con ropa para regalar. Nos pusimos más ropa y siguió el viaje pero más adelante estaban los garroteros y pararon el tren otra vez. Nos fuimos al monte a escondernos por miedo, pero las mujeres del grupo nos volvimos a subir antes de que arrancara el tren porque era de noche y estaba bien oscuro y el camino era bien feo. Los hombres desgraciados nos querían bajar "hey, hey, viejas, bájense por favor, bájense, aahhhhh, pinche viejas, ya valió", porque en ese momento la velocidad iba aumentando y ya no nos bajaron y el resto del grupo pues también se subió rápido. Qué horrible con el gran frío y qué horrible cuando toca pasar por los túneles, pero rico porque estaba calientito el ambiente y para dormirnos era bien difícil porque el aire era demasiado fuerte y eran tres túneles que había a larga distancia.

Lamentablemente, de tanto frio nos quedamos dormidos, nos pasamos del lugar de la bajada y fuimos a dar a Puebla. Puestos en dicha estación y todos con hambre, a duras penas teníamos un poco de café y azúcar, así que sacamos unas bolsas, las llenamos de agua, hicimos la fogata y a calentarla para tomarnos un poquito de café entre aproximadamente 15 personas.

Salieron dos trenes y un grupo tomamos el equivocado, y solo llegamos hasta un lugar llamado Santa Ana. Llegamos al centro de salud, las doctoras nos dieron jugo, agua, y nos dejaros descansar afuera un buen rato. Luego una doctora salió y me dijo que la acompañara. Fuimos al mercado a comprar comida, más jugos y 2 kilos de tortillas. Por todo esto ella gastó como 100 pesos y dijo que no le pesaba hacerlo, que Dios nos acompañara. Me regaló una estampilla de la Virgen de su localidad. Le agradecimos y nos dio la bendición para que todo saliera bien en el camino. Ya comidos y descansados seguimos el recorrido. Caminamos y caminamos por la línea. Una familia que tenía un puesto de venta de comida nos dio comida hasta no caber más. Qué rico. Nos despedimos y nos dijeron: "esperen, lleven esto para que coman”. Seguimos caminando y caminando. Habíamos caminado unos cuantos kilómetros y llegamos a una cancha donde descansamos y hasta nos 
dormimos de tanto cansancio. Pero luego dijo 'el güero': "hay que seguir, vamos rumbo a Apisaco".

Después de mucho caminar nos empezaron a seguir unos hombres en un carro. Nos metimos por otras calles y nos salieron adelante, así que nos tiramos por un guamil y salimos río abajo hasta que los perdimos. Luego tomamos un bus que nos sacó del peligro. Nos quedamos en un solar a comer más y a esperar que se hiciera más tarde, así que empezamos a 'echar perras' un buen rato. Pasó el descanso y continuamos nuestro recorrido. Cruzamos parte del pueblo y llegamos a una quebrada donde decidimos recolectar entre todos para pagar un taxi que nos llevó a la línea, donde nos reunimos con los demás. Ahí nos quedamos a la orilla de la línea, esperando la próxima salida del tren. Se hizo de noche y cuando el tren estaba listo para salir, los 'garroteros' empezaron a echarnos carrera a todos.

Ahí nos tocó estar varios días corriendo de un lado para otro. El tren pasaba a buena madrugada y todos adormecidos ni nos movíamos, sólo lo dejábamos pasar pues iba muy rápido y las mujeres no lo íbamos a poder agarrar. Pero llegó el momento, salimos dispuestos y no lo pudimos agarrar, así fue como decidimos caminar y caminar. Caminamos muchos kilómetros. Íbamos bastante cansados pero no nos deteníamos. No nos fijamos que había por allá una posta policial y nos sacaron carrera. La suerte fue que sólo eran tres agentes y nosotros éramos como 13 personas.

Yo ya no aguantaba más y como íbamos por unos zanjos y había zacate bastante grande me acosté y me cubrí bien. Agarraron a dos que estaban muy cerca de mí y desde ahí se escuchaba cuando la muchacha les decía que la dejaran ir por favor. Pero nada de nada y yo, arrastrándome poco a poco, logré retirarme del lugar, me alejé varios metros y ya cuando estaba larguito hasta me dormí del susto que me llevé. Cuando desperté recordé que estaba más sola que la soledad. Qué miedo. Y pienso, Dios ayúdame a encontrar a los demás compañeros de viaje. Miré a lo lejos que iba otra persona pero era tan grande el miedo de que fuera la 'jura' que no me decidí a salir. Pero luego miré al 'patudo' y qué emoción. Salí y me encontré con Juan y los demás. Ya reunidos vimos que del otro lado había una quebradita. Wendy y yo fuimos a bañarnos y a lavar la ropa que andábamos. La pusimos a secar mientras continuamos con nuestro recorrido. Esperamos que se hiciera de noche para salir de donde estábamos.

Estaba un señor arando un terreno y le preguntamos por dónde nos podíamos ir para llegar nuevamente a la línea del tren. Una vez en la línea continuamos caminando hasta que llegamos a un nuevo pueblo. Nos quedamos a la orilla de la calle. En eso pasó un carro con dos señores de alguna compañía de cable y eran tan buenas personas que nos dijeron que nos quedáramos un rato mientras ellos iban a buscar algo de comida para nosotros. Así que esperamos y nos dimos una semejante comida.

Pero había que seguir. Fueron pocos kilómetros y varias horas de caminar y parecía que no avanzábamos nada. Ya eran como las diez de la noche y nos hicimos a un lado de la línea para encender una fogata, volver a comer y dormir para salir al día siguiente a la espera del tren. Fue así como Wendy y yo planeamos salir a hacerles parada a los maquinistas y una vez que bajaran la velocidad nos subiríamos y los hombres saldrían del monte donde estaban escondidos para subirse. Lo logramos 
todos, qué emoción. Pero en nuestra próxima parada, en Lechería, vaya qué susto. Los inexpertos empezamos a bajar y cada uno que se bajaba se caía. Pero mi gran susto fue que por primera vez no me pude soltar de esa cosa y me fue dando semejante arrastrada y yo nada que me podía soltar y todos gritando "isoltate!" y yo miraba que mis pies sólo buscaban para debajo del tren. No sé cómo pero al final me solté y no me hice ni un solo rayón por gracia de Dios y la Virgen y de los santos que uno se acuerda en ese momento que existen.

Una vez que nos sacudimos el polvo la gente empezó a repartir tortas a los mojados (migrantes) que habíamos llegado en ese momento. Luego alguien se acercó y nos habló de la casa del migrante que había en Lechería. Fue así que nos fuimos en busca de dicha casa. Qué rico, había techo, agua y lo más rico que eran las camas, pues por muchos días no sabíamos lo bueno que se sentía dormir en ellas. Quizá parezca broma pero a la hora de dormir me parecía que me iba a caer de la cama. La pasamos con la madre Lupita, encargada de la casa, y muchas personas más. También pudimos avisar a nuestros familiares dónde estábamos para que no se preocuparan. Y les pedimos que nos mandaran algo de dinero pues ya no andábamos nada. Al día siguiente hubo misa para los migrantes para pedir protección, para que todo saliera bien en lo que faltaba del recorrido. Nuevamente nos tocó continuar con nuestro rumbo. Nos despedimos de la madre Lupita quien nos dio la bendición. Fuimos a la línea y al llegar al puente empezaron a llegar las personas a repartir tortas y refrescos hasta 'fulearnos' a todos. Al rato llegaron unas muchachas que parecían ser de la alta sociedad por la pinta y el carro que llevaban, "tengan más tortas y jugos". Hasta dinero nos dieron a las mujeres.

$\mathrm{Al}$ rato el tren ya estaba listo para salir y nosotros nos acercamos. Hicimos una recolecta y compramos a los 'garroteros' para que nos dejaran subir antes de que arrancara el tren. Cuando llegó el momento de salir ya estábamos arriba. En eso se acercaron los de los derechos humanos a repartir comida y frutas y a desearnos mucho éxito en lo que faltaba del camino. También nos dijeron: "una cosa más, tengan cuidado al llegar a un lugar llamado La Basurera". Tal y como nos dijeron, al llegar estaban unos hombres que le hicieron parada al tren y nos estaban obligando a bajar. Algunos del grupo se tiraron pero los nueve de nosotros no nos bajamos, les dijimos que si tenían valor que subieran a bajarnos. Nosotros íbamos en una rampla, mientras ellos se movían para un lado nosotros para otro y fue así como nos quedamos. El tren empezó a incrementar su velocidad y nos pelamos, no nos pudieron agarrar.

Para rematar, a media noche nos quedamos dormidos, nos pasamos del desvió y nos fuimos rumbo a Zacatecas. Alguien dijo, "hay que desacoplar esto", si no, a saber a dónde hubiéramos ido a parar. Lo hicieron, nos bajamos y caminamos de regreso varios kilómetros otra vez. Llegamos a otro lugar donde compramos comida e hicimos una noche más. El tren salió y ahora sí con rumbo a San Luis Potosí. Ya no recuerdo de cuántas horas fue el jalón. Pasamos con mucho frio. Pero cuando ya casi llegábamos pararon el tren y todos nos tuvimos que bajar y esconder por miedo de que fueran Los Zetas o la migra. Pero sólo fue el susto, eran los 'garroteros' haciendo inspección de rutina. Terminó y nos volvimos a subir para terminar de llegar. Una vez en el puente nos bajamos y corrimos a conseguir un taxi que nos llevó a la casa del migrante. Fueron dos viajes para llevar a todo el grupo. Una vez en la casa llegó 
el momento de registrarnos y de pasar a comer, a darnos un baño que ya mucha falta estaba haciendo. Qué rico, otra vez más a comunicarnos con nuestros familiares para darles nuestra ubicación. Luego el compañero 'el güero' se puso a hacer llamadas para localizar a un guía. Dormimos sólo una noche y al día siguiente nos recogió el guía. Habló con los familiares, hicieron el trato y mandaron el dinero. Creo que estuvimos dos noches encerrados en una casa. Nos tenían con comida y televisión, y unos colchones en los que pude tener ricos sueños.

Cuando ya nuestros familiares enviaron el dinero, nos subieron a un carro y nos dijeron que no nos preocupáramos, que más adelante habría un retén pero que todo estaría bien. Y así fue como un guía nos llevó hasta Reinosa. Al llegar a la terminal nos estaban esperando con dos carros para trasladarnos a una casa. Ya era de madrugada y llegamos a descansar mientras amanecía. La pasamos súper rico, nos tomamos unas cuantas cervezas, chisteamos vivencias del camino. Después nos trasladaron para una casa bodega. Al principio sólo éramos el grupo que veníamos juntos pero luego llevaron más gente. Hay mi madre, qué barbaridad, sí que estábamos como sardinas en lata. Y otra vez a llamar a la familia para que mandaran más dinero para hacer el cruce de la frontera. A nosotros nos costó mucho. Estuvimos más de diez días encerrados pero comiendo y bebiendo todo el día. Un día nos dijeron a los hermanos Díaz: "alístense, ya nos vamos". Así fue como fuimos al río pero no pudimos pasar y nos regresamos para la casa. Al día siguiente llevaron a otro grupo y a los hermanos Díaz nos dijeron: "no los podemos sacar porque tenemos problemas con ustedes". Los días pasaban y nosotros seguíamos ahí. Pasaban los días y llevaron a otro grupo, que según dijeron los guías los habían agarrado al no más cruzar el río.

Al final, de tanto preguntar qué pasaba con nosotros llegó el gran día pues sólo quedábamos cuatro de más de veinte. Dijeron: "vamos, los hermanos Díaz alístense, vienen por ustedes", cosa que ya no creíamos, así que nos pusimos a hacer café. Pero sí era cierto pero pasamos dando vueltas y vueltas y nada, nos llevaron a una casa y dijimos nosotros ya no nos pasaron esta noche. Pero luego recibieron una llamada y nos volvieron a sacar y esta vez sí fue. ¡Sí! Nos llevaron por toda la orilla del río y por unos lugares bien solos pero después nos bajaron y nos llevaron caminando varios minutos hasta llegar al río y en un rato los guías se pusieron a inflar las lanchas y ni siquiera tenían bombas, todo fue a puro aire de boca. Como a la una y media nos cruzaron el río y yo decía, ya estoy en Estados Unidos. Pero faltaba lo mejor, caminamos y caminamos. A lo largo oímos que iba un carro y corrimos para alejarnos del camino y escondernos. Esperamos un rato hasta que el carro regresó. Seguimos el recorrido pues faltaba mucho aún. Seguimos y seguimos, siempre a la orilla del río y cuando llegamos a un desvió escuchamos como que habían tirado unas cosas, parecían piedras o a lo mejor cuerpos pero quién sabe la verdad. Luego seguimos caminando mucho más, corrimos varias horas hasta que llegamos a donde nos estaba esperando el carro que nos llevó a Mc-calis.

Pasamos durmiendo tres noches en el monte y en un naranjal que estaba buenísimo. Qué ricas estaban las naranjas pero era larga la espera. Recuerdo que ya a la tercera noche nos fueron a recoger y nos llevaron a una casa donde dormimos un rato mientras llegaba el otro carro que resultó ser una pipa de halar combustible. Para no levantar sospechas nos llevó bastante lejos y nos tocó la parte del camino llamada desierto. Fue la caminada más grande, caminando en la noche 
y escondiéndonos en el día y comiendo sólo galletas y cosas enlatadas. Qué cosa más horrible pues sólo era harina, por lo menos para mí no era comida. Pero lo que sí llevaba era agua suficiente para apaciguar el hambre. Pero qué lástima, iba una embarazada que por ratos parecía que ya no podía pero no se detenía, era muy fuerte. Iba también una familia michoacana y una muchacha, y lo más triste fue cuando caminábamos por un arenero que parecía que no se avanzaba nada. Luego escuchamos un ruido de moto y nos ocultamos para que no nos vieran y nos quedamos escondidos otro rato. Llegó el momento de la última caminada para llegar a la casa. Ahí descansamos en unos colchones viejos. Al amanecer se nos hizo larga la espera del carro que nos llevaría a Houston. Tardó mucho en llegar porque había personas trabajando en dicha propiedad y no nos podían arriesgar. Se hizo bastante tarde y nos dieron instrucciones de cómo nos íbamos a colocar en el vehículo.

Llegó el momento, nos colocaron a las 14 personas unos en la paila acostados y cubiertos por la tapa que traía el carro y los demás como sardinas enlatadas en la cabina. Qué cosa más incómoda. A mí en lo particular, después de varias horas, el calor ya me empezaba a fatigar y la presión ya se me quería disparar y ni agua nos daban. Al mucho rato les pedí que me dieran chicles si andaban para calmarme un poco. Se detuvieron en una gasolinera y se bajaron a comprar sólo eso, chicles, que me ayudaron mucho. Una vez que llegamos a Houston medio levantamos la cabeza para ver los edificios de la ciudad. Yo pensé, hoy sí, gracias a Dios llegamos.

Pero nos sacaron de la ciudad para una casa que estaba bastante lejos. Al llegar todos encogidos nos ayudaron a bajar y al entrar miramos una alfombra tan bonita que sólo se me antojó acostarme para terminar de estirarme. Al rato nos llevaron comida y bebida, después nos dieron chance de bañarnos y lavar la ropa, que ya le hacía mucha falta la limpieza.

Luego comenzaron a entregar a las personas. Varios de los que íbamos se quedaban ahí. Ya para la noche sólo quedábamos como cinco personas. Fue entonces que empezaron a llamar a los familiares para que mandaran lo que faltaba de dinero. Pasamos una noche mientras se hacía ese trámite. Una vez que quedó todo listo nos pasaron con las personas encargadas y nuevamente llamamos para fijar el costo del traslado y las direcciones. Cenamos y dormimos una noche más. Llegó la hora de salir. Fueron 24 horas de camino, deteniéndonos sólo para ir al baño y para entrar a algún McDonalds en busca de comida. En esas 24 horas hicimos como tres paradas cortas. Luego el conductor nos volvió a pedir la dirección exacta de donde íbamos y la metió a una cosa llamada gps, que lo iba guiando por la calle que debía ir. Ya cuando estábamos cerca, llamó a Santos para ponerse de acuerdo en cuántos minutos llegaría al sitio donde nos dejaría y el color del carro en el que íbamos.

Llegamos y Santos pagó por nosotros pero no sin antes ver la mercancía. Nos despedimos y deseamos suerte a los demás, diciéndoles que fue un placer viajar con ellos. A la salida nos estaba esperando Tulio en el carro que nos llevaría a la casa pero antes fuimos a comprar algunas cosas que necesitaríamos. Santos nos dejó en casa y se regresó para el trabajo.

Llegamos y aquí estamos, buscando la forma de mejorar económicamente sin olvidar a los que han quedado atrás. Falta algo importante para mí, algunas de las cosas que me acompañaron desde Honduras hasta aquí. 